\title{
OPTIMALISASI PERSEDIAAN BAHAN BAKU DALAM PRODUKSI JAMU SINOM PADA PO ROSYADA, GRESIK, JAWA TIMUR
}

\section{INTAN RIZKY LINOVEKA ${ }^{\mathbf{1}}$, EFFY YUSWITA ${ }^{2}$, IMANIAR ILMI PARIASA ${ }^{\mathbf{3}}$}

Universitas Brawijaya

e-mail: linoveka@gmail.com

\begin{abstract}
ABSTRAK
Bahan baku adalah salah satu faktor penting yang mempengaruhi keberlangsungan proses produksi. pengendalian persediaan bahan baku juga perlu dilakukan agar terhindar dari kondisi kekurangan bahan baku dan juga bahan-bahan baku yang sudah dibeli dapat dimanfaatkan semaksimal mungkin. Maka dari itu, penelitian ini diharapkan dapat membantu usaha-usaha terkait agar dapat menentukan persediaan bahan baku yang efektif, sehingga proses produksi dapat terus berjalan. Tujuan dari penelitian ini adalah mengetahui pelaksanaan pengendalian persediaan bahan baku di PO Rosyada, menganalisis pengendalian persediaan bahan baku dengan menggunakan metode Economic Order Quantity (EOQ), menganalisis perbandingan total biaya yang dikeluarkan untuk persediaan bahan baku yang sudah dilaksanakan (sebelum metode EOQ) dan setelah menggunakan metode Economic Order Quantity (EOQ). Pendekatan penelitian menggunakan pendekatan kuantitatif. Teknik analisis data menggunakan Economic Order Quantity, Reorder Point, Safety Stock, dan Total Inventory Costs. Hasil dari penelitian ini adalah PO Rosyada masih menggunakan metode konvensional dalam melakukan pengendalian persediaan bahan baku. Setelah melakukan pengendalian bahan baku menggunakan metode EOQ, kuantitas bahan baku yang harus dipesan yaitu 92,98 kg dengan frekuensi pemesanan sebanyak 15 kali dalam setahun. Titik pemesanan kembali yaitu ketika bahan baku tersisa $32,7 \mathrm{~kg}$ dengan persediaan pengamanan sebanyak $23,82 \mathrm{~kg}$. Biaya yang dikeluarkan sebelum menggunakan EOQ adalah Rp 588.514, sedangkan setelah menggunakan EOQ adalah Rp 267.982. Hal ini dapat menghemat biaya persediaan hingga $54,46 \%$.
\end{abstract}

Kata Kunci: Persediaan, Biaya, Economic Order Quantity

\section{PENDAHULUAN}

Pengelolaan persediaan bahan baku merupakan satu hal penting dalam proses produksi. Persediaan adalah suatu aktiva yang meliputi barang-barang milik perusahaan dengan tujuan untuk dijual dalam suatu periode usaha tertentu atau persediaan barang-barang yang sedang dalam proses pengerjaan atau proses produksi ataupun persediaan bahan baku yang akan digunakan dalam suatu proses produksi (Alexandri, 2009). Oleh karena itu, pengelolaan persediaan bahan baku harus dilakukan secara efektif oleh perusahaan. Menurut Stevenson \& Chuong (2014), manajemen persediaan yang buruk akan menghambat operasi, mengurangi kepuasan pelanggan, dan meningkatkan biaya operasi.

Pengendalian persediaan bahan baku penting dilakukan perusahaan agar mencapai keuntungan yang optimal. Akan tetapi, belum semua perusahaan mengetahui pengendalian bahan baku secara tepat. Salah satu usaha yang akan diteliti adalah PO Rosyada. PO Rosyada merupakan salah satu usaha yang bergerak di bidang pembuatan minuman. Minuman yang diproduksi oleh PO Rosyada adalah jamu sinom. Bahan baku yang diperlukan untuk membuat jamu sinom salah satunya adalah kunyit.

Bahan baku yang digunakan untuk membuat minuman tersebut mudah didapatkan, namun diperlukan pengendalian persediaan agar proses produksi tetap berjalan. Selain itu, pengendalian persediaan bahan baku juga perlu dilakukan agar terhindar dari kondisi kekurangan bahan baku dan juga bahan-bahan baku yang sudah dibeli dapat dimanfaatkan semaksimal mungkin. Maka dari itu, penelitian ini diharapkan dapat membantu usaha-usaha agar dapat menentukan persediaan bahan baku yang efektif, sehingga proses produksi dapat terus berjalan. 
Tujuan dari penelitian ini adalah mendeskripsikan pelaksanaan pengendalian persediaan bahan baku di PO Rosyada, menganalisis pengendalian persediaan bahan baku dengan menggunakan metode Economic Order Quantity (EOQ) dan menganalisis perbandingan total biaya yang dikeluarkan untuk persediaan bahan baku sebelum menggunakan metode EOQ dan setelah menggunakan metode EOQ.

\section{METODE PENELITIAN}

Penelitian ini menggunakan pendekatan kuantitatif. Lokasi penelitian berada di PO Rosyada, Gresik. Penentuan lokasi dilakukan secara purposive. PO Rosyada merupakan suatu usaha yang mempelopori minuman jamu dalam kemasan di Kabupaten Gresik dan belum melakukan persediaan bahan baku dengan optimal. Penelitian ini menggunakan data Januari Desember 2019. Penentuan sampel menggunakan Judgement Sampling. Responden dalam penelitian ini adalah pemilik dari PO Rosyada karena pemilik PO Rosyada yang mengurus terkait dengan persediaan bahan baku dan memiliki pemahaman terhadap data yang diperlukan dalam penelitian ini.

Penelitian ini menggunakan data primer yang diperoleh dari wawancara dan dokumentasi. Analisis data menggunakan analisis deskriptif dan analisis pengendalian persediaan bahan baku. Analisis deskriptif digunakan untuk mendeskripsikan cara perusahaan dalam melaksanakan persediaan bahan baku yang sudah dijalankan. Analisis pengendalian persediaan bahan baku dengan cara perhitungan Economic Order Quantity (EOQ) dengan rumus sebagai berikut:

Keterangan:

$$
Q=\sqrt{\frac{2 D S}{H}}
$$

Q = Jumlah Optimum Bahan Baku Setiap Pemesanan

$\mathrm{D} \quad=$ Jumlah Bahan Baku yang Diperlukan

$\mathrm{S} \quad=$ Biaya Pemesanan

$\mathrm{H} \quad=$ Biaya Penyimpanan

Selanjutnya menghitung persediaan pengamanan (Safety Stock) dengan rumus sebagai berikut:

Keterangan:

$$
\mathrm{SS}=\mathrm{z} \sigma_{\mathrm{L}}
$$

$\mathrm{z} \quad=$ Jumlah standar deviasi untuk sebuah probabilitas pelayanan tertentu

$\sigma_{\mathrm{L}} \quad=$ Standar deviasi

Setelah menghitung persediaan pengamanan, selanjutnya menghitung Titik Pemesanan Kembali (Reorder Point). Rumus titik pemesanan kembali yaitu:

Keterangan:

$$
\mathrm{ROP}=(\mathrm{d} \times \mathrm{LT})+\mathrm{SS}
$$

$\mathrm{ROP}=$ Titik Pemesanan Kembali (Reorder Point)

$\mathrm{d} \quad=$ Permintaan

LT $\quad$ = Waktu Tunggu

SS = Safety Stock

Kemudian diperlukan juga perhitungan Total Biaya Persediaan (Total Inventory Costs) dengan rumus sebagai berikut:

$$
I C=\frac{D}{Q} S+\frac{Q}{2} H
$$

Keterangan: 


$$
\begin{array}{ll}
\text { TIC } & =\text { Total Biaya Persediaan } \\
\mathrm{D} & =\text { Permintaan } \\
\mathrm{Q} & =\text { Jumlah Pemesanan } \\
\mathrm{S} & =\text { Biaya Pemesanan } \\
\mathrm{H} & =\text { Biaya Penyimpanan }
\end{array}
$$

\section{HASIL DAN PEMBAHASAN}

\section{Hasil}

PO Rosyada didirikan pada tahun 2013 yang terletak di Jalan Belitung Raya No. 25, Kabupaten Gresik, Jawa Timur. PO Rosyada merupakan badan usaha perseorangan yang didirikan oleh Bapak Saeran. PO Rosyada merupakan suatu usaha yang memproduksi minuman jamu yaitu jamu sinom. Jamu sinom menggunakan komposisi tanaman herbal yang berfungsi untuk menjaga kesehatan tubuh. Salah satu bahan baku utama yang digunakan untuk memproduksi jamu sinom adalah kunyit.

\section{Pengendalian Persediaan Bahan Baku PO Rosyada}

Pengendalian persediaan bahan baku yang dilakukan oleh PO Rosyada dimulai dengan pengecekan ketersediaan bahan baku. Ketika persediaan bahan baku sudah mulai habis, Pemilik PO Rosyada akan melakukan pemesanan bahan baku ke supplier. Setelah memesan bahan baku yang diperlukan, kemudian mengambil bahan baku tersebut ke supplier. Supplier bahan baku kunyit diambil dari pengepul di Surabaya.

Kualitas kunyit sangat diperhatikan oleh PO Rosyada. Kunyit merupakan jenis bahan baku langsuung yang akan mempengaruhi produk yang akan dihasilkan. Kualitas kunyit mempengaruhi cita rasa jamu sinom dan warna dari jamu sinom. Kunyit yang dibeli oleh PO Rosyada merupakan kunyit pacitan yang dibeli dari pengepul di Surabaya. Kunyit yang dipilih yaitu kunyit yang besar dan berwarna cerah. Dalam satu kali pemesanan, pak Saeran membeli sekitar $50 \mathrm{~kg}$ kunyit.

Pengendalian persediaan bahan baku yang dilakukan oleh PO Rosyada masih dilakukan dengan metode konvensional, sehingga tidak ada perhitungan secara pasti jumlah pemesanan bahan baku. PO Rosyada membeli $50 \mathrm{~kg}$ kunyit dengan memperkirakan kebutuhan kunyit tanpa melakukan perhitungan sehingga terkadang terjadi kekurangan bahan baku. Selain itu, PO Rosyada melakukan pemesanan kembali ketika bahan baku yang tersedia sedikit, dan tidak memiliki perkiraan kapan bahan baku harus dipesan.

Tabel 1. Data frekuensi pemesanan, total pemesanan bahan baku dan total pemakaian bahan baku pada tahun 2019.

\begin{tabular}{llll}
\hline Bulan & Frekuensi Pemesanan & Total Pemesanan $(\mathrm{kg})$ & $\begin{array}{l}\text { Pemakaian } \\
\text { Baku }(\mathrm{kg})\end{array}$ \\
\hline Januari & 4 & 108 & 94 \\
Februari & 2 & 100 & 114 \\
Maret & 3 & 150 & 128 \\
April & 2 & 100 & 118 \\
Mei & 4 & 200 & 186 \\
Juni & 3 & 150 & 150 \\
Juli & 2 & 100 & 116 \\
Agustus & 3 & 150 & 123 \\
September & 2 & 100 & 96 \\
Oktober & 2 & 100 & 94 \\
November & 4 & 92 & 94 \\
Desember & 4 & 80 & 72 \\
\hline Jumlah & 35 & 1430 & 1385 \\
\hline Rata-Rata & 3 & 119,17 & 115,42 \\
\hline
\end{tabular}


Dari data diatas, frekuensi pembelian terbanyak terjadi pada bulan Januari, Mei, November, dan Desember. Hal ini dikarenakan pada Bulan Januari, November, dan Desember kebutuhan kunyit tidak dapat memenuhi kebutuhan bahan baku dalam sekali pemesanan. Pengepul kunyit mengalami kesulitan mencari bahan baku dikarenakan pada bulan tersebut kunyit tidak dapat ditemukan dengan mudah. Sehingga dalam sekali pemesanan hanya mendapatkan kunyit dalam kuantitas yang kecil. Sedangkan pada bulan Mei 2019 merupakan bulan Ramadhan dan perayaan Idul Fitri sehingga permintaan pada bulan tersebut meningkat dan meningkatkan frekuensi pembelian bahan baku.

Pemakaian bahan baku dalam jumlah yang banyak terjadi pada bulan Maret-Agustus. Hal ini dikarenakan pada bulan tersebut Indonesia sedang mengalami musim kemarau, sehingga kuantitas pembelian jamu sinom meningkat dan meningkatkan kuantitas pemakaian bahan baku. Pada bulan September-Februari terjadi musim hujan sehingga kuantitas pemakaian bahan baku menurun.

PO Rosyada dalam memenuhi kebutuhan bahan baku memerlukan beberapa biaya persediaan. Biaya persediaan merupakan salah satu faktor yang mempengaruhi ketersediaan bahan baku Biaya persediaan terdiri dari biaya pemesanan dan biaya penyimpanan.

Tabel 2. Biaya persediaan yang dikeluarkan oleh PO Rosyada dalam setahun.

\begin{tabular}{lll}
\hline No & Jenis Biaya & Jumlah \\
\hline 1 & Total Biaya Pemesanan & Rp 577.500 \\
2 & Total Biaya Penyimpanan & Rp 11.014 \\
\hline \multicolumn{2}{l}{ Total Biaya Persediaan } & $\operatorname{Rp~588.514}$ \\
\hline
\end{tabular}

Tabel diatas merupakan biaya persediaan yang dikeluarkan PO Rosyada. Biaya persediaan merupakan biaya yang harus dikeluarkan akibat adanya persediaan yang terdiri dari biaya pemesanan dan biaya penyimpanan (Baroto, 2002). Total biaya pemesanan yang dikeluarkan oleh PO Rosyada sebesar Rp 577.500 per tahun. Biaya pemesanan terdiri dari biaya transportasi dan biaya telpon. Satu kali pemesanan, PO Rosyada mengeluarkan biaya Rp 16.500. PO Rosyada dalam sebulan rata-rata melakukan pemesanan hingga 3 kali.

Total biaya penyimpanan yang dikeluarkan oleh PO Rosyada sebesar Rp 11.014. Biaya penyimpanan terdiri dari biaya penyusutan dan biaya listrik. Biaya penyimpanan PO Rosyada berkisar Rp 441/kg, sehingga biaya penyimpanan untuk $50 \mathrm{~kg}$ kunyit sebesar Rp 11.014.

\section{Pengendalian Persediaan Bahan Baku Menggunakan Economic Order Quantity (EOQ)}

Perhitungan EOQ menunjukkan jumlah/kuantitas pemesanan yang ekonomis dalam setiap kali pemesanan, sehingga dapat menghemat biaya yang akan dikeluarkan. Data yang diperlukan untuk menghitung EOQ antara lain kuantitas bahan baku yang diperlukan, biaya pemesanan setiap kali pemesanan, dan juga biaya penyimpanan.

Tabel 3. Hasil dari perhitungan EOQ.

\begin{tabular}{|c|c|c|c|c|c|c|}
\hline No & Bahan Baku & $\begin{array}{l}\text { Kuantitas } \\
\text { baku } \\
\text { diperlukan }(\mathrm{kg})\end{array}$ & $\begin{array}{r}\text { bahan } \\
\text { yang }\end{array}$ & $\begin{array}{l}\text { Biaya } \\
\text { Pemesanan }\end{array}$ & $\begin{array}{l}\text { Biaya } \\
\text { penyimpanan }\end{array}$ & EOQ $(\mathrm{kg})$ \\
\hline 1 & Kunyit & 115,42 & & Rp 16.500 & $\mathrm{Rp} 441$ & 92,98 \\
\hline
\end{tabular}

Hasil dari perhitungan diatas adalah pemesanan ekonomis akan tercapai jika kuantitas pemesanan sebesar 92,98 kg. Artinya, jika perusahaan ingin mengeluarkan biaya yang ekonomis, maka bahan baku yang harus dibeli adalah 92,98 $\mathrm{kg}$. Pemesanan dilakukan sebanyak 15 kali dalam setahun. Sehingga biaya persediaan yang dikeluarkan adalah sebagai berikut: 
Tabel 4. Biaya persediaan yang dikeluarkan

\begin{tabular}{lll}
\hline No & Jenis Biaya & Jumlah Biaya \\
\hline 1 & Biaya Pemesanan & Rp 247.500 \\
2 & Biaya Penyimpanan & Rp 20.482 \\
\hline Total Biaya Persediaan & Rp 267.982 \\
\hline
\end{tabular}

Biaya persediaan yang dikeluarkan oleh PO Rosyada terdiri dari biaya pemesanan dan biaya penyimpanan. Biaya pemesanan yang dikeluarkan setelah menggunakan metode EOQ adalah Rp 247.500, sedangkan biaya penyimpanan sebesar Rp 20.482. Semakin sering frekuensi pemesanan maka akan semakin besar biaya pemesanan. Sedangkan, semakin tinggi kuantitas pemesanan maka akan semakin tinggi pula biaya penyimpanan.

\section{Titik Pemesanan Kembali (Reorder Point)}

Titik pemesanan kembali berfungsi untuk menentukan waktu yang tepat untuk melakukan pemesanan bahan baku. Titik pemesanan kembali juga sebagai antisipasi agar tidak terjadi kehabisan bahan baku karena bahan baku yang tersedia digunakan setiap hari sehingga berkurang terus menerus.

Tabel 5. Data yang diperlukan untuk menghitung titik pemesanan kembali yaitu penggunaan bahan baku harian, waktu tunggu, dan persediaan pengamanan.

\begin{tabular}{llllll}
\hline $\begin{array}{l}\text { Penggunaan } \\
\text { Harian }\end{array}$ & Bahan & Baku & Waktu Tunggu & $\begin{array}{l}\text { Persediaan } \\
\text { Pengamanan }\end{array}$ & $\begin{array}{l}\text { Titik } \\
\text { Kembali }\end{array}$ \\
\hline $4,44 \mathrm{~kg}$ & & 2 hari & $23,82 \mathrm{~kg}$ & $32,7 \mathrm{~kg}$ & \\
\hline
\end{tabular}

Berdasarkan hasil perhitungan, titik pemesanan kembali yaitu 32,7 kg. Perusahaan harus memesan bahan baku kunyit ketika bahan baku tersisa 32,7 kg. Hal tersebut sebagai antisipasi kehabisan bahan baku ketika menunggu bahan baku bisa tersedia.

Tujuan dari penentuan titik pemesanan kembali adalah menjaga keseimbangan jumlah persediaan bahan baku yang ada dengan jumlah bahan baku yang dibutuhkan. Titik pemesanan kembali menghindari kekurangan bahan baku. Maka dari itu, proses produksi dapat berjalan dengan baik (Palupi, et al., 2017).

\section{Pembahasan}

Metode Economic Order Quantity (EOQ) merupakan salah satu metode yang digunakan untuk mengetahui kuantitas pemesanan yang ekonomis. Pemesanan ekonomis akan mempengaruhi biaya persediaan, sehingga biaya persediaan yang dikeluarkan akan optimal.

Tabel 6. Perbandingan biaya persediaan sebelum menggunakan EOQ dan setelah menggunakan EOQ.

\begin{tabular}{lllll}
\hline No & Jenis Biaya & Sebelum EOQ & Setelah EOQ & Presentase \\
\hline 1 & Biaya Pemesanan & Rp 577.500 & $\operatorname{Rp~247.500}$ & $57,14 \%$ \\
2 & Biaya Penyimpanan & Rp 11.014 & $\operatorname{Rp~20.482}$ & $85,96 \%$ \\
\hline Total Biaya Persediaan & Rp 588.514 & $\operatorname{Rp~267.982}$ & $54,46 \%$ \\
\hline
\end{tabular}

Tabel diatas menjelaskan perbandingan total biaya persediaan yang dikeluarkan sebelum metode EOQ dan setelah metode EOQ. Biaya pemesanan sebelum EOQ lebih besar dibandingkan setelah menggunakan EOQ. Hal ini dikarenakan frekuensi pemesanan setelah menggunakan EOQ lebih jarang dibandingkan sebelum menggunakan EOQ.

Sebelum menggunakan EOQ, jumlah frekuensi pemesanan sebanyak 35 kali sedangkan setelah menggunakan EOQ sebanyak 15 kali. Oleh karena itu, biaya pemesanan setelah menggunakan EOQ lebih kecil dibandingkan sebelum menggunakan EOQ. 
Biaya penyimpanan sebelum EOQ lebih kecil dibandingkan sesudah EOQ. Hal ini disebabkan karena kuantitas bahan baku kunyit yang dipesan dalam sekali pemesanan lebih banyak setelah menggunakan EOQ. Akan tetapi, total biaya persediaan lebih sedikit ketika menggunakan EOQ. Hal ini sesuai dengan pernyataan Syamsuddin (2007), biaya pemesanan akan semakin besar ketika frekuensi pemesanan semakin banyak, sedangkan biaya penyimpanan akan semakin besar ketika kuantitas bahan yang dipesan semakin banyak.

Setelah menggunakan metode EOQ, perusahaan dapat menghemat biaya persediaan hingga 54,46\%. Hal ini sesuai dengan pernyataan Widyastika \& Kharani (2020), Economic Order Quantity dapat meminimalkan biaya persediaan dan menghitung persediaan bahan baku yang efisen sehingga dapat menghasilkan laba yang optimal.

\section{KESIMPULAN} berikut:

Berdasarkan pembahasan yang telah dijabarkan diatas, kesimpulannya adalah sebagai

1. PO Rosyada dalam melakukan persediaan bahan baku masih secara konvensional. PO Rosyada tidak melakukan perhitungan untuk persediaan bahan baku. PO Rosyada melakukan persediaan bahan baku dengan cara mengecek persediaan bahan baku kemudian jika sudah mulai habis, PO Rosyada akan melakukan pemesanan ke supplier di Surabaya. Dalam satu kali pemesanan, PO Rosyada memesan sebanyak $50 \mathrm{~kg}$ tetapi kuantitas tersebut belum optimal untuk memenuhi persediaan bahan baku.

2. Setelah melakukan pengendalian persediaan bahan baku menggunakan metode Economic Order Quantity (EOQ), dalam satu kali pemesanan PO Rosyada memesan sebanyak 92,98 $\mathrm{kg}$ dengan 15 kali pemesanan dalam satu tahun. PO Rosyada melakukan pemesanan kembali ketika bahan baku kunyit tersisa $32,7 \mathrm{~kg}$ dengan persediaan pengamanan sebanyak $23,82 \mathrm{~kg}$.

3. Total biaya persediaan yang dikeluarkan sebelum menggunakan EOQ adalah Rp 588.514 dengan rincian biaya pemesanan sebesar Rp 577.500 dan biaya penyimpanan sebesar Rp 11.014. Sedangkan, biaya persediaan setelah melakukan EOQ adalah Rp 267.982 dengan biaya pemesanan sebesar Rp 247.500 dan biaya penyimpanan sebesar Rp 20.482. Setelah melakukan persediaan bahan baku dengan metode EOQ dapat mengurangi biaya persediaan hingga $54,46 \%$.

\section{DAFTAR PUSTAKA}

Alexandri, M.B. (2009). Manajemen Keuangan Bisnis. Bandung: Penerbit Alfabeta

Efendi, J., Hidayat, K., \& Faridz, R. (2019). Analisis Pengendalian Persediaan Bahan Baku Kerupuk Mentah Potato dan Kentang Keriting Menggunakan Metode Economic Order Quantity (EOQ). Performa: Media Ilmiah Teknik Industri, 18(2), 125-134

Palupi, V., Murni, T., Bachri, S., \& Warsono, S. (2017). Kuantitas Pemesanan Ekonmis Bahan Baku Tepung pada Usaha Roti Surya Bakery Kota Bengkulu. Management Insight, 12(1), 124-140

Stevenson, W.J., \& Chuong, S.C. (2014). Manajemen Operasi. Jakarta: Salemba Empat

Suaib, H. (2017). Nilai-Nilai Kearifan Lokal dan Modal Sosial dalam Pemberdayaan Masyarakat. Tangerang: An1mage

Syamsuddin, L. (2007). Manajemen Keuangan Perusahaan. Jakarta: Raja Grafindo Persada

Widyastika \& Khairani, M. (2020). Penerapan Metode Economic Order Quantity (EOQ) dalam Pengendaliaan Persediaan Bahan Baku pada PT Busur Inti Indo Panah. Jurnal Karismatika, 6(1), 29-44. ISSN: 2443-0366 